OPEN ACCESS

Edited by:

Philippe M. Oger,

UMR Centre National de la Recherche Scientifique 5240 Institut National des

Sciences Appliquées, France

Reviewed by:

Jens Christian Frisvad,

Technical University of Denmark,

Denmark

Ana Plemenitas,

University of Ljubljana, Slovenia

*Correspondence:

Min Xiao

xiaomin8@mail.sysu.edu.cn

Wen-Jun Li

liwenjun3@mail.sysu.edu.cn

Specialty section

This article was submitted to

Extreme Microbiology,

a section of the journal

Frontiers in Microbiology

Received: 09 February 2017 Accepted: 05 September 2017

Published: 21 September 2017

Citation:

Liu K-H, Ding X-W, Narsing Rao MP

Zhang B, Zhang Y-G, LiU F-H, Liu B-B, Xiao M and Li W-J (2017) Morphological and Transcriptomic

Analysis Reveals the Osmoadaptive

Response of Endophytic Fungus

Aspergillus montevidensis ZYD4 to

High Salt Stress.

Front. Microbiol. 8:1789.

doi: 10.3389/fmicb.2017.01789

\section{Morphological and Transcriptomic Analysis Reveals the Osmoadaptive Response of Endophytic Fungus Aspergillus montevidensis ZYD4 to High Salt Stress}

\author{
Kai-Hui Liu ${ }^{1}$, Xiao-Wei Ding ${ }^{1}$, Manik Prabhu Narsing Rao ${ }^{2}$, Bo Zhang ${ }^{1}$, Yong-Gui Zhang ${ }^{1}$, \\ Fei-Hu Liu ${ }^{3}$, Bing-Bing Liu ${ }^{2}$, Min Xiao ${ }^{2 *}$ and Wen-Jun $\mathrm{Li}^{2,4 *}$ \\ ${ }^{1}$ School of Biological Science and Engineering, Shaanxi University of Technology, Hanzhong, China, ${ }^{2}$ State Key Laboratory \\ of Biocontrol and Guangdong Provincial Key Laboratory of Plant Resources, School of Life Sciences, Sun Yat-Sen University, \\ Guangzhou, China, ${ }^{3}$ School of Life Sciences, Yunnan University, Kunming, China, ${ }^{4}$ Key Laboratory of Biogeography and \\ Bioresource in Arid Land, Xinjiang Institute of Ecology and Geography, Chinese Academy of Sciences, Ürúmqi, China
}

Halophilic fungi have evolved unique osmoadaptive strategies, enabling them to thrive in hypersaline habitats. Here, we conduct morphological and transcriptomic response of endophytic fungus (Aspergillus montevidensis ZYD4) in both the presence and absence of salt stress. Under salt stress, the colony morphology of the $A$. montevidensis ZYD4 changed drastically and exhibited decreased colony pigmentation. Extensive conidiophores development was observed under salt stress; conidiophores rarely developed in the absence of salt stress. Under salt stress, yellow cleistothecium formation was inhibited, while glycerol and compatible sugars continued to accumulate. Among differentially expressed unigenes (DEGs), 733 of them were up-regulated while 1,619 unigenes were down-regulated. We discovered that genes involved in the accumulation of glycerol, the storage of compatible sugars, organic acids, pigment production, and asexual sporulation were differentially regulated under salt stress. These results provide further understanding of the molecular basis of osmoadaptive mechanisms of halophilic endophytic fungi.

Keywords: transcriptome, halophilic endophytic fungi, Aspergillus montevidensis, high-salt stress, osmoadaptive mechanisms

\section{INTRODUCTION}

Extremophilic microorganisms not only survive, but can grow optimally under rough conditions which are considered harsh and inhospitable for other life forms as well (Mesbah and Wiegel, 2012). Hypersaline environment is one of the examples of such extreme environments (Wood, 2015). Generally, high salinity represents high-osmotic stress, which triggers cytoplasm shrinkage and causes lethal damage to salt-sensitive microbes (Koch, 1984; Morris et al., 1986). However, some microbes learn to cope with these high salt concentrations by developing special strategies (Oren, 2002). In hypersaline environments, bacteria are considered to be the only populated microorganisms (Gunde-Cimerman et al., 2009); however, the report by Gunde-Cimermana et al. (2000) show the presence of fungi in saline environments. Since then, many fungal spp. were 
reported from different saline environments (Plemenitaš et al., 2008; Gunde-Cimerman et al., 2009).

Fungi use different strategies to overcome salt stress, such as morphological change (Zajc et al., 2013), reinforcement of cell walls, accumulation of osmolytes like glycerol, and change in genetic structures (Duran et al., 2010; Kralj Kuncic et al., 2010; Kis-Papo et al., 2014). Changes to salt stress at the transcriptomic level are still intricate, and the molecular mechanisms are not well-known. With the development of RNA-sequencing, it is easy to detect transcriptomic responses in a given species to varying experimental conditions (Schweder and Hecker, 2004; Dalmolin et al., 2012; Taymaz-Nikerel et al., 2016).

Next-generation sequencing technology (Illumina RNAseq) enables highly sensitive and accurate quantification of expression, thus providing a myriad of transcript data with high resolution, high quality, and low costs (Riccombeni and Butler, 2012). It has been widely applied in non-model and model species, such as, Aspergillus nidulans, Hortaea werneckii, and Wallemia ichthyophaga, examining hundreds of stress-tolerance genes (Redkar et al., 1996; Petrovic et al., 2002; Zajc et al., 2013). Although, studies are carried out to understand salt stress-tolerance genes in fungi, there are only a few reports on response of endophytic fungi to high-salt stress. In this study, we made an attempt to isolate an endophytic fungus from a hypersaline region and evaluate its morphological and transcriptomic response under salt stress.

\section{MATERIALS AND METHODS}

\section{Isolation and Identification of Endophytic Fungal Strain ZYD4}

Medicago sativa L. grew in hypersaline environment (Huama lake region, Northern Shaanxi, China) was chosen as a source plant for the isolation of endophytic fungi. The endophytic strain ZYD4, was isolated using yeast extract-peptone-dextrose (YPD) agar (Difco) from the stems of Medicago sativa $\mathrm{L}$. which were surface sterilized by following the protocols of Li et al. (2009) and Salam et al. (2017). For the identification, genomic DNA from strain ZYD4 was extracted by following the protocol of Hinrikson et al. (2005). ITS fragments of strain ZYD4 were amplified using the primers, ITS1 and ITS4 (White et al., 1990).

The analysis of sequences was done at Blast-n site at NCBI server (http://www.ncbi.nlm.nih.gov/BLAST).

The phylogenetic tree was constructed by neighbor-joining (NJ) (Saitou and Nei, 1987) method using MEGA 5.0 software package (Tamura et al., 2011) after multiple alignment of the sequences using CLUSTAL_X program (Thompson et al., 1997). Kimura's two parameter model was used to calculate evolutionary distance matrices (Kimura, 1980). Bootstrap analysis was performed with 1,000 replications (Felsenstein, 1985).

\section{Morphological Response of Endophytic Strain ZYD4 to Salt Stress}

The morphological response of endophytic strain ZYD4 to salt stress was evaluated at salt concentrations ranging from 0 to $4.5 \mathrm{M}$ (at an interval of $1.5 \mathrm{M}$ ) using YPD agar at $28^{\circ} \mathrm{C}$ for 6 days.

\section{Evaluation of Salt Stress on the Biosynthesis of Pigment and Accumulation of Glycerol and Compatible Sugars}

To evaluate salt stress on the biosynthesis of pigment and accumulation of glycerol and compatible sugars, we grew strain ZYD4 in the presence and absence of $3 \mathrm{M} \mathrm{NaCl}$. The collected mycelium was washed three times with sterilized distilled water and freeze-dried at $-30^{\circ} \mathrm{C}$.

The mycelium was thoroughly ground in liquid nitrogen. The pigment was extracted with methanol (Liu et al., 2015) and monitored by UV-visible spectrophotometer (Shimadzu UV1750 , Japan) using $\beta$-Carotene and flavoglaucin as standard.

Glycerol and compatible sugars were extracted in sterilized distilled water using sonicator $(350 \mathrm{~W}, 1 \mathrm{~min})$ performed on the ice bath followed by centrifugation at $10,000 \mathrm{rpm}$ for 10 $\min$ at $4{ }^{\circ} \mathrm{C}$. All extracts were filtered through a $0.22-\mu \mathrm{m}$ filter before the examination. Glycerol and compatible sugars were determined using UV-visible spectrophotometer (Shimadzu UV1750, Japan) by following the protocols of Kuhn et al. (2015) and Laurentin and Edwards (2003).

\section{RNA Extraction, Library Construction, and Illumina Sequencing}

We statically grew endophytic strain ZYD4 on YPD broth at $28^{\circ} \mathrm{C}$ for 6 days. The fungal mycelium was harvested and induced under salt stress by adding $3 \mathrm{M} \mathrm{NaCl}$ at $28^{\circ} \mathrm{C}$ for $30 \mathrm{~min}$. Total RNA from salt-stress induced and non-induced mycelium was extracted using the Trizol reagent (Invitrogen, Carlsbad, CA, USA), according to manufacturer's instructions. The RNA samples were treated with DNase I for $30 \mathrm{~min}$ at $37^{\circ} \mathrm{C}$ to remove genomic DNA contamination. The quantity and integrity of the total RNAs were verified using an Agilent 2100 bioanalyzer. The cDNA libraries were developed according to manufacturer's instructions (Illumina, Inc., San Diego, CA, USA), and sequenced on the Illumina HiSeq 2000 platform at Beijing Genomics Institute (Shenzhen, China).

\section{De novo Assembly and Analysis}

Before the assembly, raw reads were cleaned by removing adaptor sequences, low-quality reads, and reads with unknown nucleotides $>5 \%$. All clean reads were de novo assembled into contigs using the short-read assembling program Trinity (Grabherr et al., 2011). The contigs were pooled to build into de Brujin graphs by Chrysalis. Contigs from the same transcript and the distances between these contigs were detected by a paired-end sequencing strategy. Unigenes from each samples assembly were further processed with sequence-clustering software to remove sequence splicing and redundancy. The unigenes were divided into clusters (CL prefix) and singletons (unigene prefix) by gene family clustering.

\section{Functional Annotation and Differential Expression Analysis}

All unigenes were compared against NCBI non-redundant protein database (NR), the NCBI non-redundant nucleic acid database (NT), the Swiss-Prot database, the Clusters 
of Orthologous Groups (COG) database, and the Kyoto Encyclopedia of Genes and Genomes (KEGG) database with an $E<10^{-5}$. The best aligned results were applied to determine sequence direction of unigenes. The Gene Ontology (GO) was analyzed with Blast2GO software (Conesa et al., 2005). The GO functional classification was performed using WEGO software (Ye et al., 2006). Protein coding region prediction of the unigenes was searched by BLASTx $(E<0.00001)$ against NCBI NR, SwissProt, KEGG, and COG. When unigene was not aligned to any of the above databases, ESTS was used to predict its coding regions and ascertain its sequence direction (Iseli et al., 1999). Differentially expressed unigenes were filtered using a threshold of false discovery rate $(\mathrm{FDR} \leq 0.001)$ and an absolute $\log 2$ ratio $\geq 1$. These differential expression unigenes were further mapped onto known pathways using the KEGG pathway annotation.

\section{qPCR}

qPCR was performed to validate the differential expression of randomly selected genes involved in salt-tolerance on a 7500 Real-Time PCR System (Applied Biosystems, USA) under the following conditions: $95^{\circ} \mathrm{C}$ for $30 \mathrm{~s}$, followed by 40 cycles of $95^{\circ} \mathrm{C}$ for $15 \mathrm{~s}$ and $60^{\circ} \mathrm{C}$ for $40 \mathrm{~s}$. The q-PCR mixture $(20 \mu \mathrm{l})$ comprised of $10 \mu \mathrm{l}$ of SYBR ${ }^{\circledR}$ Select Master Mix (Applied Biosystems, USA), $10 \mathrm{ng}$ of cDNA, primers $(0.4 \mu \mathrm{M}$ each; Table S1), and RNasefree water. All PCR reactions were run in duplicate for each gene along with the endogenous $18 \mathrm{~S}$ rRNA reference gene. The $2^{-\Delta \Delta \mathrm{Ct}}$ method (Livak and Schmittgen, 2001) was employed to calculate the gene expression levels in salt with and without treated samples.

\section{RESULTS}

\section{Identification of Endophytic Fungal Strain ZYD4}

The BLAST result showed that, endophytic strain ZYD4 shared $100 \%$ similarity with Aspergillus montevidensis. The obtained sequences were submitted to GenBank under the accession number MF062488. In NJ tree (Figure 1) strain ZYD4 was grouped with $A$. montevidensis. Based on the above, strain ZYD4 was identified as $A$. montevidensis. The strain ZYD4 was deposited in China General Microbiological Culture Collection Center under the deposition number CGMCC 3.15762.

\section{Morphological Response of}

\section{A. montevidensis ZYD4 under Salt Stress}

Under salt stress, the morphological characters such as colony shape, color, size, and conidial head formation of A. montevidensis ZYD4 changed (Figures $\mathbf{2 b}-\mathbf{d}$, Table 1). Under salt stress, the mycelium was loose while compact in absence of salt stress. The width of hyphae decreased under salt stress (Table 1). Under salt stress, A. montevidensis ZYD4 colonies were olive green in the center and white at the margin while in the absence of salt stress, colonies were yellow to gray black in center and golden yellow at the margin. The conidial head was extensively developed in the presence of salt stress, while rarely formed in the absence of salt stress. Formation of yellow

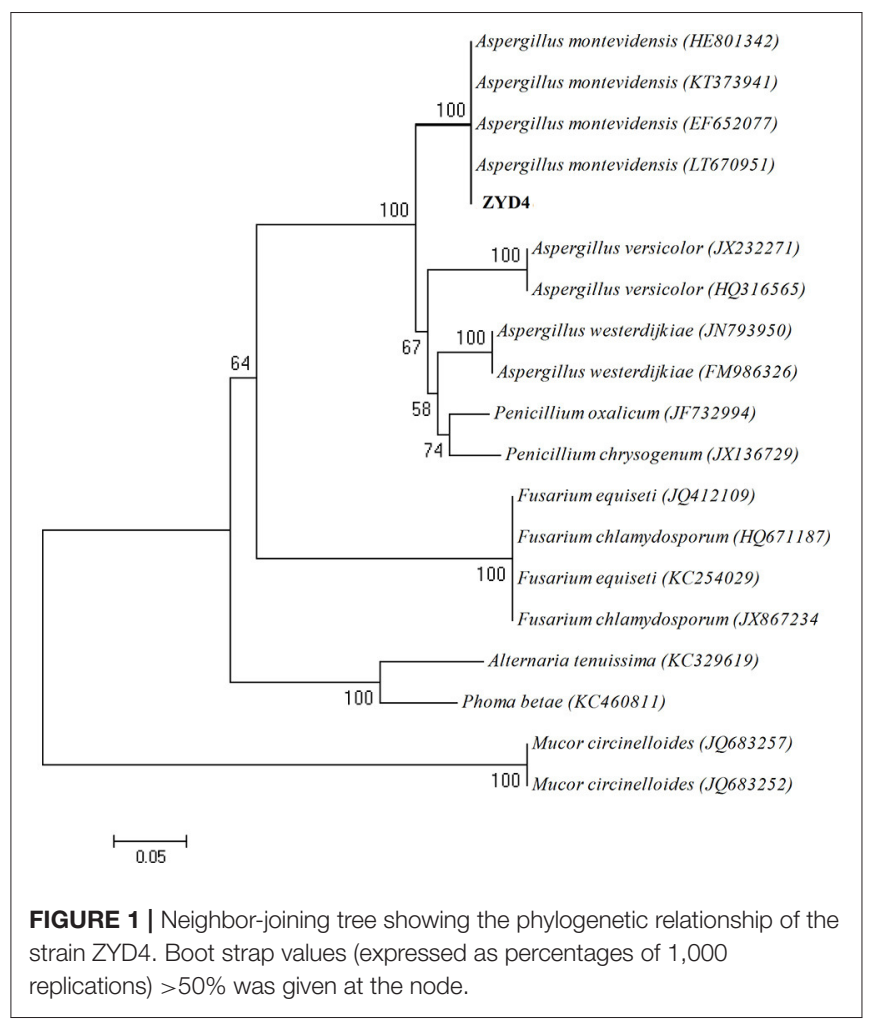

cleistothecium was dramatically inhibited with an increase of salt stress (Figures 2e-h, Table 1).

\section{Evaluation of Salt Stress on the Biosynthesis of Pigment and Accumulation of Glycerol and Compatible Sugars}

Figure 3 shows UV-visible spectra of pigment biosynthesis analysis which suggest that, $A$. montevidensis ZYD4 grown under salt stress did not show any pigment production, while in absence of salt stress pigment production was observed.

The content of glycerol in salt treated mycelium was 2.5 -fold high when compared to salt untreated mycelium (Figure 4A). Similarly, the contents of total compatible sugars in salt treated mycelium was 2.0-fold high when compared to salt untreated mycelium (Figure 4B).

\section{Illumina Sequencing and De novo Assembly}

To explore osmoadaptive strategies, cDNA libraries of A. montevidensis ZYD4 (from salt with and without treated mycelium) were sequenced using the Illumina Hiseq 2000 platform. The raw reads obtained from salt with and without induced mycelium were submitted into GenBank under the accession numbers SRX1794941 and SRX1794940 respectively. After the removal of the adapter sequences, unknown, and low-quality sequences about 104,004,358 clean reads (average length $90 \mathrm{nt}$ ) were obtained from raw reads with GC percentage between 50.57 and $51.63 \%$. 



FIGURE 2 | Morphological profile of $A$. montevidensis ZYD4 on solid medium supplemented with varying concentrations of $\mathrm{NaCl}$ (a,e) without NaCl; (b,f) $1.5 \mathrm{M}$ NaCl; (c,g) $3 \mathrm{M} \mathrm{NaCl}$; (d,h) $4.5 \mathrm{M} \mathrm{NaCl}$.

These clean reads were de novo assembled (Table 2 ) resulting in 34,341, and 28,503 contigs for salt without and with treated samples, with a mean length of 595, and $657 \mathrm{nt}$ and an N50 length of 1,717 , and 1,789 nt respectively.

After further clustering and assembly, 27,797 unigenes for salt untreated sample and 24,157 unigenes for salt treated sample, with an average length of 1,199 , and 1,253 nt, and N50 length of 2,283 , and 2,268 nt respectively were obtained. There were 46,464 unigenes with the length $\geq 500 \mathrm{nt}$, and 41,844 unigenes with the length $\geq 1,000 \mathrm{nt}$. The length distribution of these contigs and unigenes were shown in Table 2.

\section{Functional Annotation}

A total of 18,267 unigenes were annotated, among them 17,713, $12,197,12,018$, and 9,029 showed high similarities to the known genes in NR, SwissProt, KEGG, and COG databases. The NR annotation and $\mathrm{E}$-value distribution (Figure 5A) of significant hits $\left(E<1.0 \times 10^{-45}\right)$ showed that $71.6 \%$ of the sequences had strong homologies, $19.2 \%$ of the sequences had a high degree of homologies with $E<1.0 \times 10^{-15}$, and $70.9 \%$ of the sequences had high similarity $>60 \%$, while $21.9 \%$ showed a similarity range between 40 and $60 \%$ (Figure 5B). Nearly $62.9 \%$ of the annotated unigenes assigned to top BLAST hits were closely related to Aspergillus species, namely Aspergillus oryzae (15.1\%), Aspergillus terreus (9.4\%), Aspergillus clavatus (7.7\%), Aspergillus kawachii (7.1\%), Aspergillus niger (7\%), and Aspergillus flavus (4.6\%; Figure 5C).

\section{GO and COG Classification}

FDR $\leqq 0.001$ and $\log 2$ ratio $\geqq 1$ as the threshold were used to verify the significance of gene expression differences. Based on these criteria, a total of 2,352 unigenes were differentially expressed in presence and absence of salt stress. Among differentially expressed unigenes (DEGs), 733 unigenes were upregulated while 1,619 unigenes were down-regulated (Figure 6). The expression patterns of some DEGs were validated by RT-PCR (Figure 7). DEGs were assigned to $44 \mathrm{GO}$ terms consisting of three domains namely biological process, molecular function, and cellular component (Figure 8). The representative distributions of the GO terms for biological processes include cellular process, metabolic process, and single-cell process. A majority of molecular function was composed of cells, cell part, and organelle. Cellular component mainly included catalytic activity, and binding. To verify the effectiveness of annotation, COG classification of DEGs was performed resulting in 25 COG groups. Of these, general function prediction cluster (16.7\%) was the dominant group, followed by replication, recombination and repair (8.66\%), translation, ribosomal structure and biogenesis ( $7.45 \%)$, and RNA processing and modification (0.64\%; Figure 9).

\section{KEGG Pathway Analysis}

To analyze the salt stress functions of DEGs, we mapped DEGs to 100 reference canonical pathways in KEGG database. The significantly enriched DEGs were mainly involved in 20 pathways, such as metabolic pathways (ko01100, 409 unigenes, $32.8 \%$ ), biosynthesis of secondary metabolites (ko01110, 202 unigenes, 16.2\%), ribosome (ko03010, 117 unigenes, 9.38\%), starch and sucrose metabolism (ko00500, 79 unigenes, 6.34\%), amino sugar and nucleotide sugar metabolism (ko00520, 68 unigenes, 5.45\%), oxidative phosphorylation (ko00190, 
TABLE 1 | Morphological profile of $A$. montevidensis ZYD4 on solid medium supplemented with varying salt concentration.

\begin{tabular}{|c|c|c|}
\hline Isolate & $\begin{array}{c}\mathrm{NaCl} \text { in } \\
\text { media (M) }\end{array}$ & Morphology \\
\hline \multirow[t]{4}{*}{$\begin{array}{l}\text { A. montevidensis } \\
\text { ZYD4 }\end{array}$} & 0 & $\begin{array}{l}\text { Compact mycelium; colony was yellow to gray } \\
\text { black in the center and golden yellow at the } \\
\text { margin; the branched hyphae are septate, and } \\
\text { measure about } 2.5-6.25 \mu \mathrm{m} \text { in width; } \\
\text { conidiophores chain rarely formed from } \\
\text { swelling conidial heads; spherical conidia of } \\
3.75 \times 3.75 \mu \mathrm{m} \text { size; yellow cleistothecia } \\
\text { extensively developed; ascospores measure } \\
\text { about } 1.67-2.77 \times 2.08-3.15 \mu \mathrm{m} \text {. }\end{array}$ \\
\hline & 1.5 & $\begin{array}{l}\text { Loose mycelium; colony was yellow to gray } \\
\text { black in the center and gray-black at the } \\
\text { margin; the branched hyphae are septate, and } \\
\text { measure about } 2.5-6.25 \mu \mathrm{m} \text { in width; gray } \\
\text { pigmented conidial heads developed; } \\
\text { spherical/oval conidia of } 2.5-4.0 \times \\
3.75-5.0 \mu \mathrm{m} \text { size; yellow cleistothecia } \\
\text { extensively produced; ascospores measure } \\
\text { about } 1.67-2.77 \times 2.08-3.15 \mu \mathrm{m} \text {. }\end{array}$ \\
\hline & 3 & $\begin{array}{l}\text { Loose mycelium; colony was olive green in the } \\
\text { center and white at the margin; the branched } \\
\text { hyphae are septate and measure about } \\
2.5-6.25 \mu \mathrm{m} \text { in width; olive green/white } \\
\text { pigmented conidial heads extensively } \\
\text { developed; spherical/oval conidia of } 2.5-4.0 \times \\
3.75-5.0 \mu \mathrm{m} \text { size. }\end{array}$ \\
\hline & 4.5 & $\begin{array}{l}\text { Loose and white mycelium; the branched } \\
\text { hyphae are septate and measure about } \\
2.0-2.5 \mu \mathrm{m} \text { in width; gray-green pigmented } \\
\text { conidial heads extensively developed; } \\
\text { spherical/oval conidia of } 2.5-4.0 \times 3.0-5.0 \mu \mathrm{m} \\
\text { size. }\end{array}$ \\
\hline
\end{tabular}

56 unigenes, 4.49\%), glycolysis/gluconeogenesis (ko00010, 29 unigenes, 2.33\%), glycerophospholipid metabolism (ko00564, 26 unigenes, 2.09\%), and cell cycle (ko04111 and ko04113, 38 unigenes, $1.6 \%$ ). The result of KEGG pathway analysis showed multiple significant enriched pathways which were implicated in response to high salt stress in A. montevidensis ZYD4.

\section{Genes Involved in the Development of Asexual Sporulation}

After exposure to high-salt stress, A. montevidensis ZYD4 extensively developed conidiophores and asexual spores (Figure 2). Correspondingly, unigenes homologous to known genes, controlling asexual development of $A$. montevidensis were also up-regulated (Table 3).

\section{Genes Involved in the Biosynthesis of Yellow Pigment}

The yellow pigment produced by A. montevidensis ZYD4 was decreased under salt stress. DEGs related to the biosynthesis of carotenoids in A. montevidensis ZYD4 was summarized in Table 3. It was observed that, unigenes homologous to geranylgeranyl diphosphate synthase, hydroxymethylglutarylCoA (HMG-CoA) synthase, and farnesyl pyrophosphate
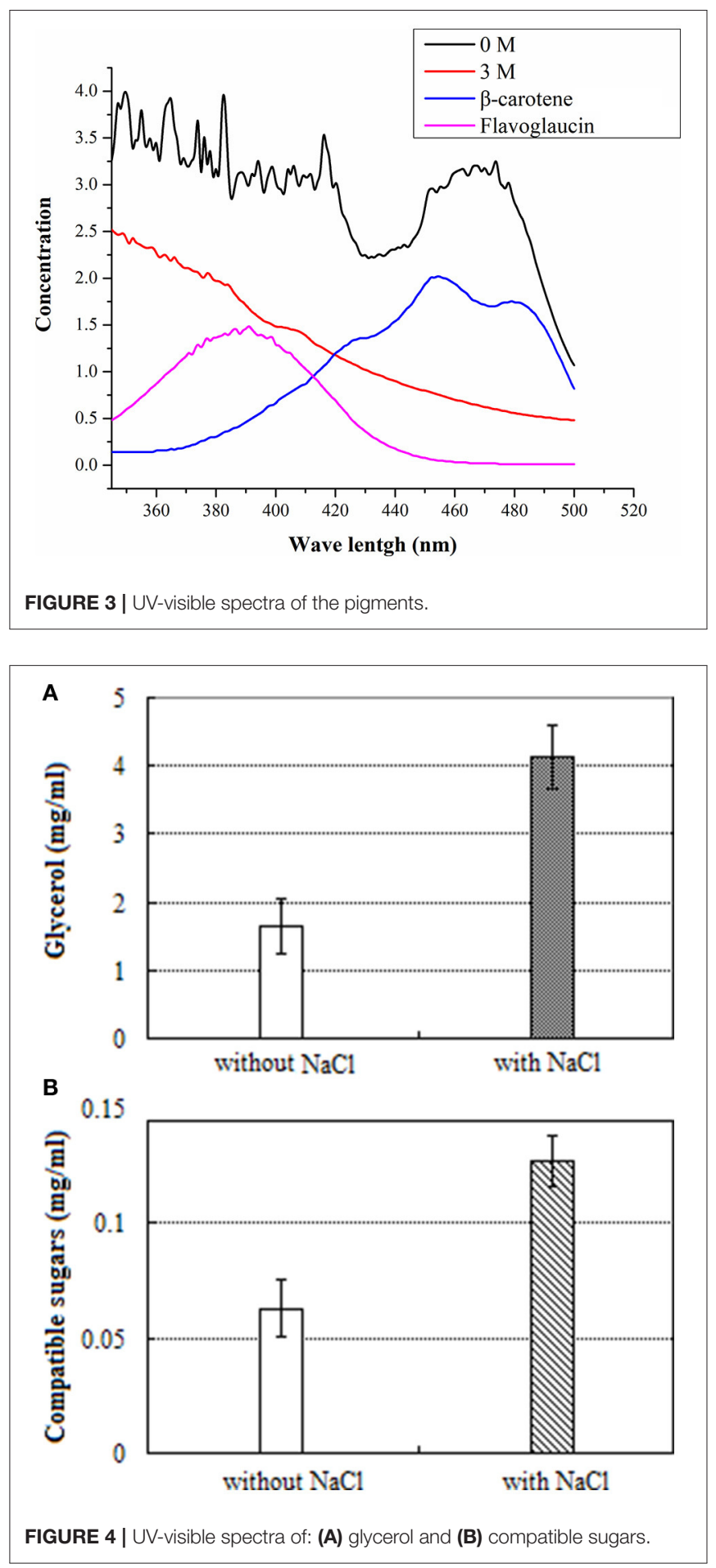

synthase were down-regulated by 1.1-, 13.1-, and 11.4-fold respectively.

\section{Genes Involved in the Accumulation of Glycerol}

Under salt stress, the expression of one unigene encoding glycerol-3-phosphate dehydrogenase (which participates in the 
glycerol biosynthetic pathway) was elevated by 1.4-fold (Table 3), however, one unigene encoding glycerol dehydrogenase (which converts glycerol into dihydroxyacetone) showed 1.4-fold decrease of expression. Unigenes coding for enzymes responsible for glycerol biosynthesis were up-regulated by 1.1 - to 1.4fold, while unigenes encoding diacylglycerol O-acyltransferase, triacylglycerol lipase, and phospholipase D (these participate in the further transformation of glycerol) were down-regulated by 1.4 - to 11.0 -fold. These results indicated that glycerol was

TABLE 2 | Summary of $A$. montevidensis ZYD4 transcriptome assembly.

\begin{tabular}{lcc}
\hline & $\begin{array}{c}\text { A. montevidensis } \\
\text { with NaCl }\end{array}$ & $\begin{array}{c}\text { A. montevidensis } \\
\text { without NaCl }\end{array}$ \\
\hline Number of contings & 28,503 & 34,341 \\
Total length of contings (nt) & $18,739,029$ & $20,437,448$ \\
Mean length conting (nt) & 657 & 595 \\
N50 contig length (nt) & 1789 & 1717 \\
Total unigenes & 24,157 & 27,797 \\
Total length of unigenes (nt) & $30,268,028$ & $33,330,542$ \\
Mean length of unigene (nt) & 1253 & 1199 \\
N50 unigene length (nt) & 2268 & 2283 \\
Distinct clusters & 8,643 & 9,765 \\
Distinct singletons & 15,514 & 18,032
\end{tabular}

accumulated in A. montevidensis ZYD4 to create a cellular osmotic equilibrium in high-salt conditions.

\section{Genes Involved in the Biosynthesis of Compatible Sugars}

Under salt stress, expression of unigenes homologous to hexokinase, 6-phosphofructo-2-kinase, trehalose-phosphate synthase, and mannose-6-phosphate isomerase increased by 1.0 - to 2.2-fold (Table 3). Remarkably, 19 DEGs for the further conversion of glucose-6-phosphate into other intermediates via the down-stream pathway of glycolysis and TCA cycle were suppressed up to 10.8 - to 13.9 -fold. In addition, unigenes responsible for the further transformation of acetyl-CoA (a metabolic intermediate of sugar) into fatty acids, and carotenoids were down-regulated. The above results obtained were consistent with UV-visible spectroscopic analysis (Figure 4B).

\section{Genes Involved in the Biosynthesis of Organic Acids}

Unigenes of proline oxidase and pyrroline-5-carboxylate dehydrogenase increased the expression by 3.6 , and 1.9 -fold respectively in salt induced samples (Table 3). However, unigenes of glutamate dehydrogenase, and glutamine synthetase (can divide glutamate into glutamine, $\mathrm{NH}_{4}^{+}$and 2-oxo-glutarate) was suppressed more than 11-fold. Moreover, expression level of
A E-value distribution

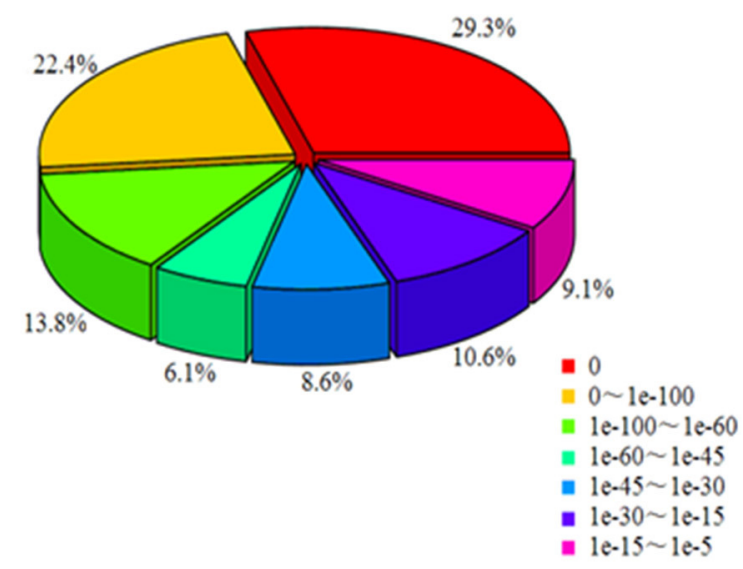

C Species distribution

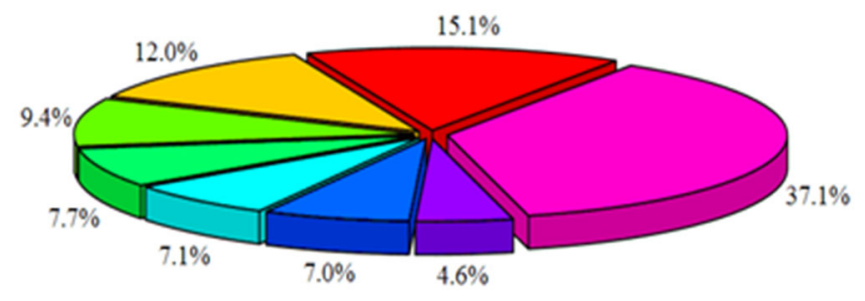

B Similarity distribution

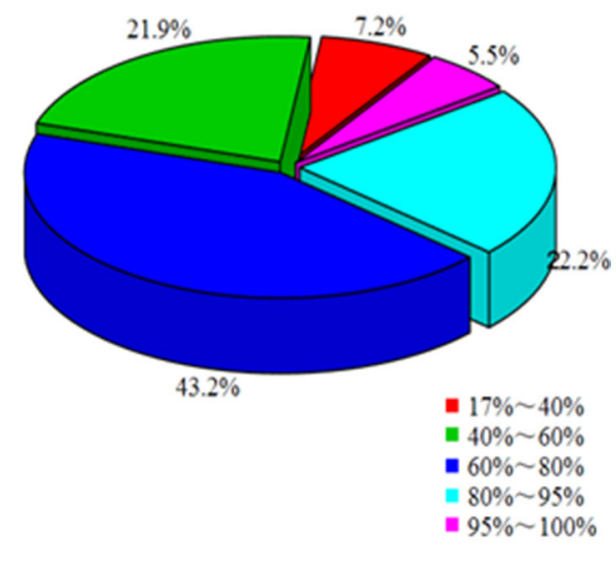

- Aspergillus onzae RIB 40

= Neosartony a fischeri NRRL 181

= Aspergillus terreus FGSC A1156

- Aspergillus clavatus NRRL

- Aspergillus kawachii IFO 4308

- Aspergillus niger CBS 513.88

- Aspergillus flavus NRRL3357

- Other

FIGURE 5 | Characteristics of homology search of unigenes against $\mathrm{Nr}$ databases. (A) E-value distribution of BLASTx matches to the unigenes against Nr; (B) Similarity in distribution of BLASTx matches to the unigenes against Nr; (C) Species distribution of BLASTx matches to the unigenes against Nr. 


\section{Expression Level Aspergillus OA vs Aspergillus $1 \mathrm{~A}$}
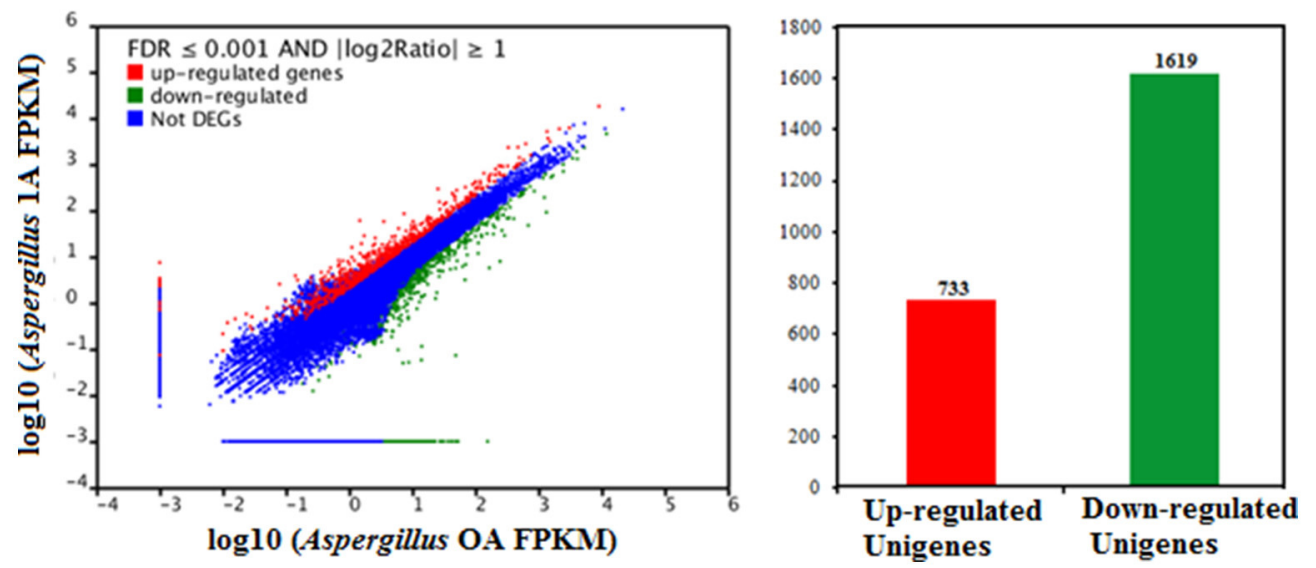

FIGURE 6 | Comparison of gene expression levels in the control and the salt-treated samples. Aspergillus OA represents salt untreated sample, and Aspergillus $1 \mathrm{~A}$ represents salt treated samples. Fragments Per Kilobase of transcript per Million fragments mapped abbreviated as FPKM.

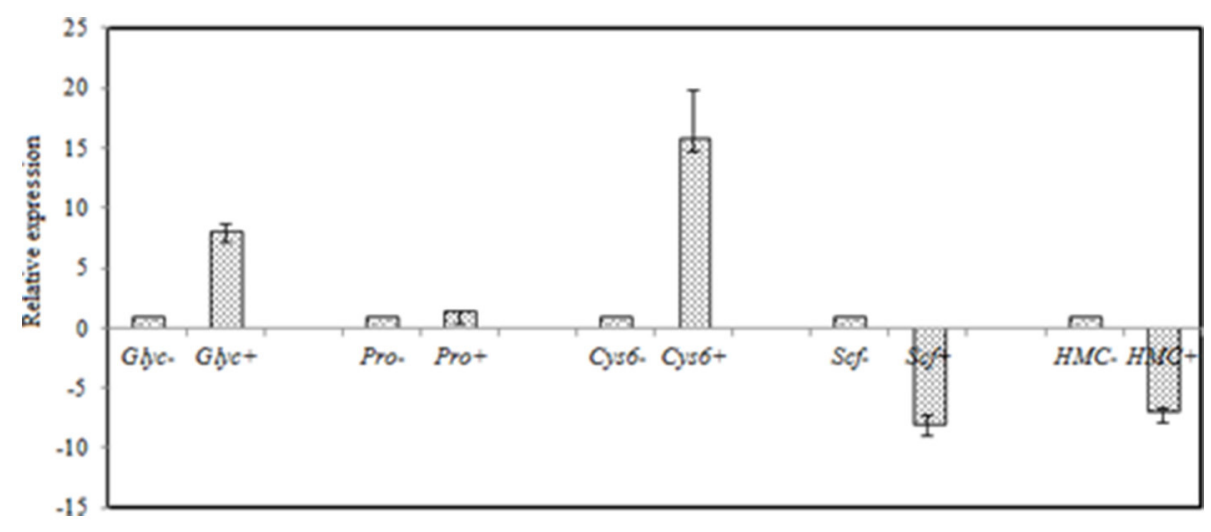

FIGURE 7 | RT-qPCR validation of selected genes with significant differential expression in the control and the salt-treated samples. RT-qPCR data are mean $\pm S D$ from three biological replicates. "-," and "+" indicates A. montevidensis was induced without, and with $3 \mathrm{M} \mathrm{NaCl}$. DEGs putatively encoded glycerol-3-phosphate dehydrogenase (Glyc), proline oxidase (Pro), Zn(II)2Cys6 transcription factor (Cys6), SCF ubiquitin ligase (Scf), and hydroxymethylglutaryl-CoA (HMG-CoA) synthase $(H M C)$.

one unigene, encoding glutamate decarboxylase, was augmented by 5 -fold. A detailed up and down regulated genes involved in biosynthesis of organic acids were mentioned in Table 3.

\section{DISCUSSION}

Survival and growth of microorganisms in saline environments require numerous morphological ecotypes and adaptations. Salt stress causes changes in colony morphology, colony pigmentation, and cell wall structure (Kralj Kuncic et al., 2010). Hence, in the present study we evaluated the morphological changes caused by salt stress. In the absence of salt stress, mycelium of A. montevidensis ZYD4 was compact while loose in the presence of salt stress. Further, the hyphae width was reduced under salt stress. Similar to our results, fungal hyphae growth was effected under salt stress (Matsuda et al., 2006). Under salt stress, A. montevidensis ZYD4 conidial heads were extensively developed while without salt stress conidial heads were rarely formed.

It is widely known that carotenoids and flavoglaucin are responsible for yellow, bright red, and orange hues of fungal colonies (Davoli and Weber, 2002; Christaki et al., 2013; Dufosse et al., 2014). A. montevidensis ZYD4 subjected to salt stress showed drastic change in colony color. Under salt stress, colonies of A. montevidensis ZYD4 were olive green in the center, and white at the margin. Colonies without salt stress, were yellow to gray black in the center, and golden yellow at the margin. Similar to our result, Kralj Kuncic et al. (2010) observed change in the colony color when Wallemia sp. subjected to salt stress.

The pigment production showed drastic variation under salt stress. The methanolic extract obtained from A. montevidensis 


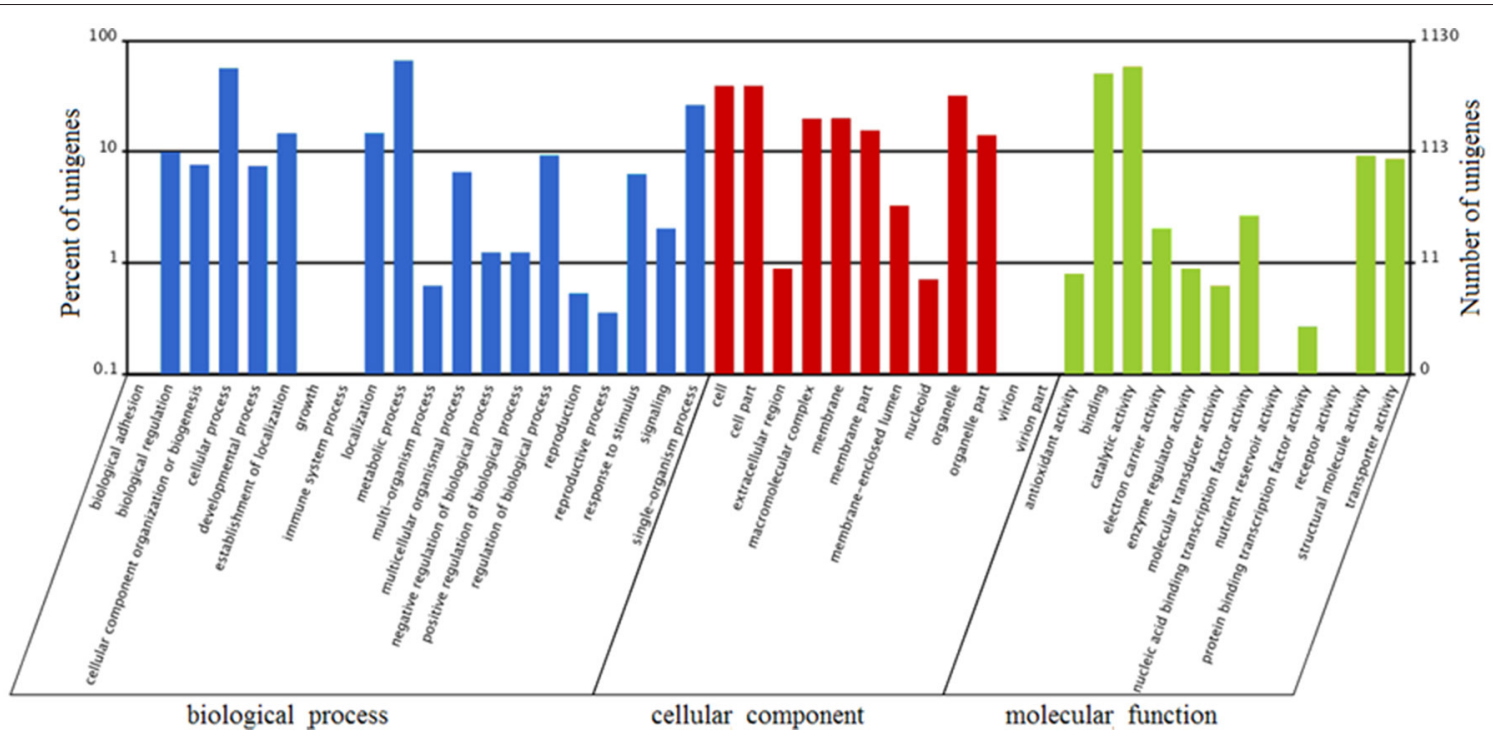

FIGURE 8 | Gene Ontology (GO) terms enrichment of unigenes of $A$. montevidensis ZYD4 at transcriptome level. The results were summarized in three main categories: biological process, cellular component, and molecular function. The right y-axis presents the number of unigenes in the category, while the left $y$-axis presents the percentage of a specific category of unigenes in that category.

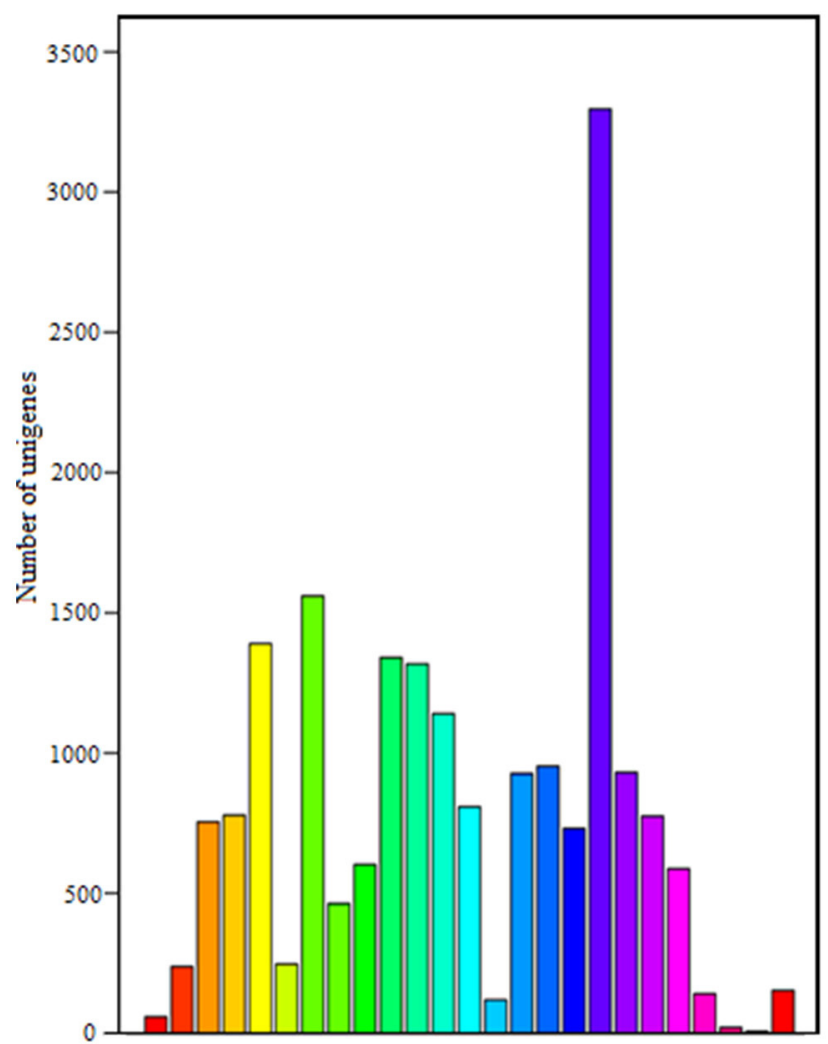

A B C DEFGH I K L M NOPRST UVWYZ
A: RNA processing and modification

B: Chromatin structure ans dynamics

$C$ : Energy production and conversion

D: Cell cycle control, cell division, chromosome partitioning

E: Amino acid transport and metabolism

F: Nucleotide transport and metabolism

G: Carbohydrate transport and metabolism

$\mathrm{H}$ : Coenzyme transport and metabolism

I: Lipid transport and metabolism

$\mathrm{J}$ : Translation, ribosomal structure and biogenesis

$\mathrm{K}$ : Transcription

L: Replication, recombination and repair

$\mathrm{M}$ : Cell wall/membrane/envelope biogenesis

$\mathrm{N}$ : Cell motility

$\mathrm{O}$ : Posttranslational modification, protein turnover, chaperones

$P$ : Inorganic ion transport and metabolism

Q: Secondary metabolites biosynthesis, transport and catabolism

$\mathrm{R}$ : General function prediction only

$\mathrm{S}$ : Function unknown

$T$ : Signal transduction mechanisms

$\mathrm{U}$ : Intracellular trafficking, secretion, and vesicular transport

$\mathrm{V}$ : Defense mechanisms

W: Extracellular structures

Y: Nuclear structues

Z: Cytoskeleton

Function class

FIGURE 9 | COG classification of unigenes. A total of 7,576 unigenes had a COG classification among the 25 categories. The capital letters on the x-axis indicate the $\mathrm{COG}$ categories as listed on the right of the histogram. 
TABLE 3 | Summary of some differently expressed genes of $A$. montevidensis in response to high-salt stress.

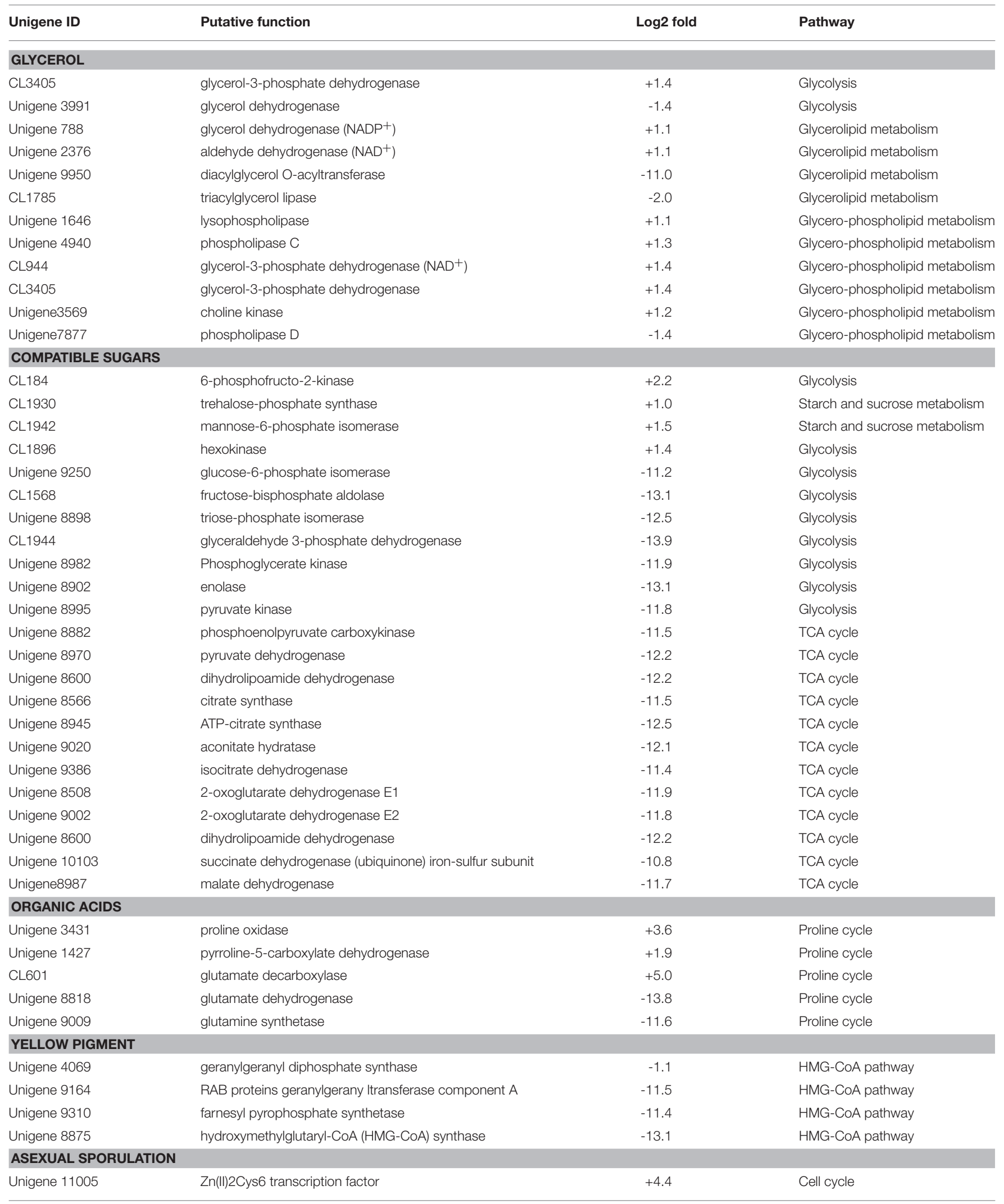


TABLE 3 | Continued

\begin{tabular}{|c|c|c|c|}
\hline Unigene ID & Putative function & Log2 fold & Pathway \\
\hline CL66 & G1/S-specific cyclin Cln1 & +1.5 & Cell cycle \\
\hline CL2000 & cell cycle arrest protein BUB2 & +1.3 & Cell cycle \\
\hline CL707 & DNA replication licensing factor $\mathrm{mcm} 7$ & +1.0 & Cell cycle \\
\hline Unigene 5683 & Spindle assembly checkpoint component MAD1 & +1.6 & Cell cycle \\
\hline Unigene 7664 & nuclear condensin complex subunit Smc4 & -2.9 & Cell cycle \\
\hline CL1202 & Spore-wall fungal hydrophobin dewA & +1.6 & Cell cycle \\
\hline
\end{tabular}

ZYD4 grown in absence of $3 \mathrm{M} \mathrm{NaCl}$ showed peaks from 400 to $490 \mathrm{~nm}$, indicating the presence of carotenoids (Klassen and Foght, 2008; Liu et al., 2015), while strain ZYD4 grown in presence of $3 \mathrm{M} \mathrm{NaCl}$ did not show any significant peak, indicating the absence of carotenoid. Similar to our results, Plemenitaš et al. (2008) found decreased pigment production in $H$. werneckii subjected to high salinity. Further, unigenes homologous to geranylgeranyl diphosphate synthase, hydroxymethylglutaryl-CoA (HMG-CoA) synthase, and farnesyl pyrophosphate synthase were down-regulated under salt stress.

Generally, enhanced expression of these genes increases fungal carotenoid content, which are made from acetyl-CoA through the HMG-CoA pathway (Davoli and Weber, 2002; Alcaino et al., 2014; Nagy et al., 2014). Therefore, down-regulated expression of these unigenes showed decreased synthesis of pigments in A. montevidensis ZYD4, and in turn regulated accumulation of intracellular glucose-6-phosphate by slowing down the metabolic flow of acetyl-CoA. The results suggest that the decrease of pigments was an osmoadaptive strategy.

Cleistothecium formation was dramatically inhibited with an increase of salt stress (Figures $\mathbf{2} \mathbf{e}-\mathbf{h}$, Table $\mathbf{1}$ ), suggesting that hypersaline condition triggered a transit from sexual to asexual state. The enhanced asexual development in A. montevidensis ZYD4 was critical in the life cycle being the primary means for survival under salt stress. Similar effect was observed in the marine-derived Aspergillus glaucus under high-salt stress (Liu et al., 2017).

In this study, we also evaluated genes involved in the development of asexual sporulation. The unigene 11005 encoding a $\mathrm{Zn}(\mathrm{II})_{2} \mathrm{Cys}_{6}$ transcription factor was upregulated by 4.4-fold. This factor plays a crucial role for asexual sporulation in different filamentous fungi (Vienken and Fischer, 2006; Chung et al., 2013; Gil-Duran et al., 2015; Son et al., 2016). Seven unigenes with significant identities to CLN3,CIB3/4, CIB1/2, Bub2, Lte1, Mcm7, and Mad1 required for cell cycle progression through mitosis were up regulated by 1.0 - to 2.3 fold, except for unigene 9493, encoding for ubiquitin ligase (E3) complex SCF subunit which was significantly down-regulated by 11.1-fold.

Unlike halophilic Archaea, halotolerant fungi do not accumulate high internal ion concentrations when grown in hypersaline conditions, but rather they counterbalance the osmotic imbalance by the accumulation of polyols (Kogej et al., 2005). Some studies suggest that glycerol accumulation is necessary for living cells to keep osmotic homeostasis and alleviate adverse effects of toxic $\mathrm{Na}^{+}$ions (Kogej et al., 2007). In this study, we found that unigenes involved in the accumulation of glycerol were extensively enhanced in expression, however unigenes participated in the transformation of glycerol were down-regulated, suggesting that glycerol was accumulated in cells upon the hypersaline shock. Expression of two unigenes, encoding for glycerol-3-phosphate dehydrogenase, and 6-phosphofructo-2-kinase was augmented by 1.4 , and 2.2-fold respectively. These unigenes are essential for glycerol biosynthesis and cell proliferation in hyperosmotic environments (Dihazi et al., 2004; Lenassi et al., 2011). The spectrophotometric analysis demonstrated that the content of glycerol was increased by 2.5 fold (Figure $4 \mathbf{A}$ ) which was consistent with the results of Kogej et al. (2007).

The storage of the compatible sugars and organic acids play a key role for osmotic adjustment of eukaryotic cells (Gagneul et al., 2007; Rosa et al., 2009; Plemenitaš et al., 2014; Sos-Hegedus et al., 2014; Henry et al., 2015). The spectrophotometric analysis demonstrated that the content of compatible sugars was increased by 2.0-fold under salt stress (Figure 4B), suggesting that compatible sugars play a significant role in $A$. montevidensis ZYD4 against high salt stress. Further, under salt stress A. montevidensis ZYD4 showed 1.0- to 2.2-fold increase in the expression of unigenes homologous to hexokinase, 6-phosphofructo-2-kinase, trehalose-phosphate synthase, and mannose-6-phosphate isomerase which participate in the upper pathways of glycolysis, TCA cycle, starch, and sucrose pathway. Nineteen DEGs for the further conversion of glucose-6-phosphate into other intermediates via the down-stream pathway of glycolysis and TCA cycle were suppressed. Unigenes of proline oxidase and pyrroline-5-carboxylate dehydrogenase that generates glutamate via proline cycle increased the expression by 3.6, and 1.9-fold in the salt-induced samples. Moreover, expression level of one unigene encoding glutamate decarboxylase was augmented by 5 -fold which was associated with the conversion of glutamate into $\gamma$-aminobutyric acid (GABA) suggesting that GABA was accumulated in the salt-induced fungal cells. 


\section{AUTHOR CONTRIBUTIONS}

$\mathrm{WL}, \mathrm{KL}$, and MX designed research and project outline. KL, $\mathrm{XD}$, and $\mathrm{YZ}$ performed growth and morphology observation. KL, $\mathrm{XD}, \mathrm{MN}$, and $\mathrm{BZ}$ performed transcriptome sample preparation and sequencing. KL, MX, and MN provided the gene functional annotation and differential expression analysis. KL, MN, BL, MX, and WL drafted the manuscript. All authors read and approved the final manuscript.

\section{ACKNOWLEDGMENTS}

We are very grateful to the reviewers for their valuable suggestions and comments for greatly improving the manuscript. This work was financed by the National Natural Science Foundation Program of China (No. 31100017), Program of Agricultural Scientific and Technological

\section{REFERENCES}

Alcaino, J., Romero, I., Niklitschek, M., Sepulveda, D., Rojas, M. C., Baeza, M., et al. (2014). Functional characterization of the Xanthophyllomyces dendrorhous farnesyl pyrophosphate synthase and geranylgeranyl pyrophosphate synthase encoding genes that are involved in the synthesis of isoprenoid precursors. PLoS ONE 9:e96626. doi: 10.1371/journal.pone.0096626

Christaki, E., Bonos, E., Giannenas, I., and Florou-Paneri, P. (2013). Functional properties of carotenoids originating from algae. J. Sci. Food. Agric. 93, 5-11. doi: 10.1002/jsfa.5902

Chung, H., Choi, J., Park, S. Y., Jeon, J., and Lee, Y. H. (2013). Two conidiationrelated $\mathrm{Zn}$ (II)2Cys6 transcription factor genes in the rice blast fungus. Fungal Genet. Biol. 61, 133-141. doi: 10.1016/j.fgb.2013.10.004

Conesa, A., Gotz, S., Garcia-Gomez, J. M., Terol, J., Talon, M., and Robles, M. (2005). Blast2GO: a universal tool for annotation, visualization and analysis in functional genomics research. Bioinformatics 21, 3674-3676. doi: 10.1093/bioinformatics/bti610

Dalmolin, R. J., Gelain, D. P., Klamt, F., Castro, M. A., and Moreira, J. C. (2012). Transcriptomic analysis reveals $\mathrm{pH}$-responsive antioxidant gene networks. Front. Biosci. 4, 1556-1567. doi: 10.2741/s352

Davoli, P., and Weber, R. W. S. (2002). Carotenoid pigments from the red mirror yeast, Sporobolomyces roseus. Mycologist 16, 102-108. doi: 10.1017/S0269915X02001027

Dihazi, H., Kessler, R., and Eschrich, K. (2004). High osmolarity glycerol (HOG) pathway-induced phosphorylation and activation of 6phosphofructo-2-kinase are essential for glycerol accumulation and yeast cell proliferation under hyperosmotic stress. J. Biol. Chem. 279, 23961-23968. doi: 10.1074/jbc.M312974200

Dufosse, L., Fouillaud, M., Caro, Y., Mapari, S. A., and Sutthiwong, N. (2014). Filamentous fungi are large-scale producers of pigments and colorants for the food industry. Curr. Opin. Biotechnol. 26, 56-61. doi: 10.1016/j.copbio.2013.09.007

Duran, R., Cary, J. W., and Calvo, A. M. (2010). Role of the osmotic stress regulatory pathway in morphogenesis and secondary metabolism in filamentous fungi. Toxins 2, 367-381. doi: 10.3390/toxins 2040367

Felsenstein, J. (1985). Confidence limits on phylogenies: an approach using the bootstrap. Evolution 39, 783-791. doi: 10.1111/j.1558-5646.1985.tb00420.x

Gagneul, D., Ainouche, A., Duhaze, C., Lugan, R., Larher, F. R., and Bouchereau, A. (2007). A reassessment of the function of the so-called compatible solutes in the halophytic plumbaginaceae Limonium latifolium. Plant. Physiol. 144, 1598-1611. doi: 10.1104/pp.107.099820

Gil-Duran, C., Rojas-Aedo, J. F., Medina, E., Vaca, I., Garcia-Rico, R. O., Villagran, S., et al. (2015). The pczl gene, which encodes a $\mathrm{Zn}(\mathrm{II}) 2 \mathrm{Cys} 6$ protein, is involved in the control of growth, conidiation, and conidial germination
Innovation of Shaanxi Province (S2018-YF-YBNY-0042), Shaanxi University of Technology (SLGQD16-06, SLGQD1607), China Postdoctoral Science Foundation Grant (No. 2015M580748) and China Postdoctoral Special Foundation (No. 2016T90811). WL was also supported by Xinjiang Uygur Autonomous Region regional coordinated innovation project (Shanghai cooperation organization science and technology partnership program) (No. 2017E01031) and Project Supported by Guangdong Province Higher Vocational Colleges \& Schools Pearl River Scholar Funded Scheme (2014).

\section{SUPPLEMENTARY MATERIAL}

The Supplementary Material for this article can be found online at: http://journal.frontiersin.org/article/10.3389/fmicb. 2017.01789/full\#supplementary-material

in the filamentous fungus Penicillium roqueforti. PLoS ONE 10:e0120740. doi: 10.1371/journal.pone.0120740

Grabherr, M. G., Haas, B. J., Yassour, M., Levin, J. Z., Thompson, D. A., Amit, I., et al. (2011). Full-length transcriptome assembly from RNA-Seq data without a reference genome. Nat. Biotechnol. 29, 644-652. doi: 10.1038/nbt.1883

Gunde-Cimerman, N., Ramos, J., and Plemenitas, A. (2009). Halotolerant and halophilic fungi. Mycol. Res. 113(Pt 11), 1231-1241. doi: 10.1016/j.mycres.2009.09.002

Gunde-Cimermana, N., Zalarb, P., De Hoogc, S., and Plemenitasd, A. (2000). Hypersaline waters in salterns-natural ecological niches for halophilic black yeasts. FEMS. Microbiol. Ecol. 32, 235-240. doi: 10.1016/S0168-6496(00)00032-5

Henry, C., Bledsoe, S. W., Griffiths, C. A., Kollman, A., Paul, M. J., Sakr, S., et al. (2015). Differential role for trehalose metabolism in salt-stressed maize. Plant. Physiol. 169, 1072-1089. doi: 10.1104/pp.15.00729

Hinrikson, H. P., Hurst, S. F., De Aguirre, L., and Morrison, C. J. (2005). Molecular methods for the identification of Aspergillus species. Med. Mycol. 43(Suppl. 1), S129-S137. doi: 10.1080/13693780500064722

Iseli, C., Jongeneel, C. V., and Bucher, P. (1999). ESTScan: a program for detecting, evaluating, and reconstructing potential coding regions in EST sequences. Proc. Int. Conf. Intell. Syst. Mol. Biol. 99, 138-148.

Kimura, M. (1980). A simple method for estimating evolutionary rates of base substitutions through comparative studies of nucleotide sequences. J. Mol. Evol. 16, 111-120. doi: 10.1007/BF01731581

Kis-Papo, T., Weig, A. R., Riley, R., Persoh, D., Salamov, A., Sun, H., et al. (2014). Genomic adaptations of the halophilic dead Sea filamentous fungus Eurotium rubrum. Nat Commun. 5:3745. doi: 10.1038/ncomms4745

Klassen, J. L., and Foght, J. M. (2008). Differences in carotenoid composition among Hymenobacter and related strains support a tree-like model of carotenoid evolution. Appl. Environ. Microbiol. 74, 2016-2022. doi: 10.1128/AEM.02306-07

Koch, A. L. (1984). Shrinkage of growing Escherichia coli cells by osmotic challenge. J. Bacteriol. 159, 919-924.

Kogej, T., Ramos, J., Plemenitas, A., and Gunde-Cimerman, N. (2005). The halophilic fungus Hortaea werneckii and the halotolerant fungus Aureobasidium pullulans maintain low intracellular cation concentrations in hypersaline environments. Appl. Environ. Microbiol. 71, 6600-6605. doi: 10.1128/AEM.71.11.6600-6605.2005

Kogej, T., Stein, M., Volkmann, M., Gorbushina, A. A., Galinski, E. A., and GundeCimerman, N. (2007). Osmotic adaptation of the halophilic fungus Hortaea werneckii: role of osmolytes and melanization. Microbiology 153, 4261-4273. doi: 10.1099/mic.0.2007/010751-0

Kralj Kuncic, M., Kogej, T., Drobne, D., and Gunde-Cimerman, N. (2010). Morphological response of the halophilic fungal genus Wallemia to high salinity. Appl. Environ. Microbiol. 76, 329-337. doi: 10.1128/AEM.02318-09 
Kuhn, J., Müller, H., Salzig, D., and Czermak, P. (2015). A rapid method for an offline glycerol determination during microbial fermentation. Electron. J. Biotechnol. 18, 252-255. doi: 10.1016/j.ejbt.2015.01.005

Laurentin, A., and Edwards, C. A. (2003). A microtiter modification of the anthrone-sulfuric acid colorimetric assay for glucose-based carbohydrates. Anal. Biochem. 315, 143-145. doi: 10.1016/S0003-2697(02)00704-2

Lenassi, M., Zajc, J., Gostinčar, C., Gorjan, A., Gunde-Cimerman, N., and Plemenitaš, A. (2011). Adaptation of the glycerol-3-phosphate dehydrogenase Gpd1 to high salinities in the extremely halotolerant Hortaea werneckii and halophilic Wallemia ichthyophaga. Fungal Biol. 115, 959-970. doi: 10.1016/j.funbio.2011.04.001

Li, J., Zhao, G. Z., Qin, S., Zhu, W. Y., Xu, L. H., and Li, W. J. (2009). Streptomyces sedi sp. nov., isolated from surface-sterilized roots of Sedum sp. Int. J. Syst. Evol. Microbiol. 59, 1492-1496. doi: 10.1099/ijs.0.007534-0

Liu, L., Zhou, E. M., Jiao, J. Y., Manikprabhu, D., Ming, H., Huang, M. J., et al. (2015). Hymenobacter mucosus sp. nov., isolated from a karst cave soil sample. Int. J. Syst. Evol. Microbiol. 65, 4121-4127. doi: 10.1099/ijsem.0.000550

Liu, S., Li, J., Wu, Y., Ren, Y., Liu, Q., Wang, Q., et al. (2017). De novo transcriptome sequencing of marine-derived Aspergillus glaucus and comparative analysis of metabolic and developmental variations in response to salt stress. Genes Genomics 39, 317-329. doi: 10.1007/s13258-016-0497-0

Livak, K. J., and Schmittgen, T. D. (2001). Analysis of relative gene expression data using real-time quantitative PCR and the $2^{-\Delta \Delta C T}$ method. Methods 25 , 402-408. doi: 10.1006/meth.2001.1262

Matsuda, Y., Sugiyama, F., Nakanishi, K. and Ito, S. I. (2006). Effects of sodium chloride on growth of ectomycorrhizal fungal isolates in culture. Mycoscience 47, 212-217. doi: 10.1007/S10267-006-0298-4

Mesbah, N. M., and Wiegel, J. (2012). Life under multiple extreme conditions: diversity and physiology of the halophilic alkalithermophiles. Appl. Environ. Microbiol. 78, 4074-4082. doi: 10.1128/AEM.00050-12

Morris, G. J., Winters, L., Coulson, G. E., and Clarke, K. J. (1986). Effect of osmotic stress on the ultrastructure and viability of the yeast Saccharomyces cerevisiae. J. Gen. Microbiol. 132, 2023-2034. doi: 10.1099/00221287-132-7-2023

Nagy, G., Farkas, A., Csernetics, A., Bencsik, O., Szekeres, A., Nyilasi, I., et al. (2014). Transcription of the three HMG-CoA reductase genes of Mucor circinelloides. BMC Microbiol. 14:93. doi: 10.1186/1471-2180-14-93

Oren, A. (2002). "Adaptation of halophilic archaea to life at high salt concentrations," in Salinity: Environment-Plants-Molecules, eds A. Lauchli and U. Luttge (Springer), 81-96.

Petrovic, U., Gunde-Cimerman, N., and Plemenitas, A. (2002). Cellular responses to environmental salinity in the halophilic black yeast Hortaea werneckii. Mol. Microbiol. 45, 665-672. doi: 10.1046/j.1365-2958.2002.03021.x

Plemenitaš, A., Lenassi, M., Konte, T., Kejžar, A., Zajc, J., Gostinčar, C., et al. (2014). Adaptation to high salt concentrations in halotolerant/halophilic fungi: a molecular perspective. Front. Microbiol. 5:199. doi: 10.3389/fmicb.2014.00199

Plemenitaš, A., Vaupotic, T., Lenassi, M., Kogej, T., and Gunde-Cimerman, N. (2008). Adaptation of extremely halotolerant black yeast Hortaea werneckii to increased osmolarity: a molecular perspective at a glance. Stud. Mycol. 61, 67-75. doi: 10.3114/sim.2008.61.06

Redkar, R. J., Lemke, P. A., and Singh, N. K. (1996). Altered gene expression in Aspergillus nidulans in response to salt stress. Mycologia 88, 256-263.

Riccombeni, A., and Butler, G. (2012). Role of genomics and RNA-seq in studies of fungal virulence. Curr. Fungal Infect. Rep. 6, 267-274. doi: $10.1007 / \mathrm{s} 12281-012-0104-\mathrm{z}$

Rosa, M., Prado, C., Podazza, G., Interdonato, R., Gonzalez, J. A., Hilal, M., et al. (2009). Soluble sugars-metabolism, sensing and abiotic stress: a complex network in the life of plants. Plant Signal. Behav. 4, 388-393. doi: $10.4161 /$ psb.4.5.8294
Saitou, N., and Nei, M. (1987). The neighbor-joining method: a new method for reconstructing phylogenetic trees. Mol. Biol. Evol. 4, 406-425.

Salam, N., Khieu, T. N., Liu, M. J., Vu, T. T., Ky, S. C., Quach, N. T., et al. (2017). Endophytic actinobacteria associated with Dracaena cochinchinensis Lour: isolation, diversity, and their cytotoxic activities. Biomed. Res. Int. 2017:1308563. doi: 10.1155/2017/1308563

Schweder, T., and Hecker, M. (2004). "Monitoring of stress responses," in Physiological Stress Responses in Bioprocesses, ed S.-O. Enfors (Berlin; Heidelberg: Springer), 47-71.

Son, H., Fu, M., Lee, Y., Lim, J. Y., Min, K., Kim, J. C. et al. (2016). A novel transcription factor gene FHS1 is involved in the DNA damage response in Fusarium graminearum. Sci. Rep. 6:21572. doi: 10.1038/srep 21572

Sos-Hegedus, A., Juhasz, Z., Poor, P., Kondrak, M., Antal, F., Tari, I., et al. (2014). Soil drench treatment with $ß$-aminobutyric acid increases drought tolerance of potato. PLoS ONE. 9:e114297. doi: 10.1371/journal.pone.01 14297

Tamura, K., Peterson, D., Peterson, N., Stecher, G., Nei, M., and Kumar, S. (2011). MEGA5: molecular evolutionary genetics analysis using maximum likelihood, evolutionary distance, and maximum parsimony methods. Mol. Biol. Evol. 28, 2731-2739. doi: 10.1093/molbev/msr121

Taymaz-Nikerel, H., Cankorur-Cetinkaya, A., and Kirdar, B. (2016). Genomewide transcriptional response of Saccharomyces cerevisiae to stress-induced perturbations. Front. Bioeng. Biotechnol. 4:17. doi: 10.3389/fbioe.2016. 00017

Thompson, J. D., Gibson, T. J., Plewniak, F., Jeanmougin, F., and Higgins, D. G. (1997). The CLUSTAL_X windows interface: flexible strategies for multiple sequence alignment aided by quality analysis tools. Nucleic Acids Res. 25, 4876-4882. doi: 10.1093/nar/25.24.4876

Vienken, K., and Fischer, R. (2006). The Zn(II)2Cys6 putative transcription factor NosA controls fruiting body formation in Aspergillus nidulans. Mol. Microbiol. 61, 544-554. doi: 10.1111/j.1365-2958.2006.05257.x

White, T. J., Bruns, T., Lee, S., and Taylor, J. (1990). "Amplification and direct sequencing of fungal ribosomal RNA genes for phylogenetics," in PCR Protocols: A Guide to Methods and Applications, eds M. A. Innis, D. H. Gelfand, J. J. Sninsky, and T. J. White (San Diego, CA: Academic Press), $315-322$.

Wood, J. M. (2015). Bacterial responses to osmotic challenges. J. Gen. Physiol. 145, 381-388. doi: 10.1085/jgp.201411296

Ye, J., Fang, L., Zheng, H., Zhang, Y., Chen, J., Zhang, Z., et al. (2006). WEGO: a web tool for plotting GO annotations. Nucleic Acids Res. 34, W293-W297. doi: 10.1093/nar/gkl031

Zajc, J., Liu, Y., Dai, W., Yang, Z., Hu, J., Gostincar, C., et al. (2013). Genome and transcriptome sequencing of the halophilic fungus Wallemia ichthyophaga: haloadaptations present and absent. BMC Genomics. 14:617. doi: 10.1186/1471-2164-14-617

Conflict of Interest Statement: The authors declare that the research was conducted in the absence of any commercial or financial relationships that could be construed as a potential conflict of interest.

Copyright (๑) 2017 Liu, Ding, Narsing Rao, Zhang, Zhang, Liu, Liu, Xiao and Li. This is an open-access article distributed under the terms of the Creative Commons Attribution License (CC BY). The use, distribution or reproduction in other forums is permitted, provided the original author(s) or licensor are credited and that the original publication in this journal is cited, in accordance with accepted academic practice. No use, distribution or reproduction is permitted which does not comply with these terms. 